\title{
Interpretation of the Teaching Revelation of Self-interest in Rashomon
}

\author{
Zhang Li \\ School of Foreign Languages, Xi'an University, Shaanxi, China, 710065
}

Keywords: Akutagawa Ryunosuke; Rashomon; Self-interest; Human Nature's Good and Evil

Abstract: Rashomon is the famous work of Akutagawa Ryunosuke, in which reveals the essence of "evil" that human beings show under the influence of self-interest by the psychological changes of the dismissal of the people in the war era. This article analyzes the self-interested ideas expressed in the article by comparing the original book of Rashomon with its original material of Konjaku Monogatari. Through comparative analysis, the author aims to provide a reference for the complexity of the transformation of good and evil driven by self-interest in the role of debut, hoping that students will have a certain understanding of human nature in the process of learning.

Akutagawa Ryunosuke (1892-1927) is a famous novelist in modern Japan. In the first half of the 20th century, he, together with Mori Ougai and Natsume Soseki, were called the three great masters of the Japanese literary world. His works, known as short stories, have left many masterpieces. Rashomon is one of the masterpieces. This novel tells of a young man under the Rashomon who was dismissed by the owner and had nowhere to go and describes the whole process from his struggle to the fall, which shows the darkness of the heart driven by human beings under the influence of self-interest and at the same time deeply criticizes the various dark sides of society.

\section{A comparison of the original works in Akutagawa's Rashomon and Konjaku Monogatari}

Akutagawa Ryunosuke's works are novel and conceived, revealing the darkness and abomination of humanity in the real world. It is very artistic. As an early masterpiece of Akutagawa Ryunosuke, Rashomon occupies an important position in the history of Japanese literature. This article is based on Konjaku Monogatari and deepens the content of the story through Akutagawa's own superior skills, uncovering the weakness of human nature without any concealment. And this weakness is self-interest.

Unlike the identity of the protagonist robber described in the Japanese classical story Konjaku Monogatari, the identity of the protagonist in Rashomon is the person who is dismissed by the owner under the ridiculous Rashomon. This difference has profound meaning and we should carefully taste it. If the protagonist is a robber, when he is in a dilemma, we can imagine that he is robbing the old man's clothes, and we may feel that this is normal. And Akutagawa added some new content on the basis of the original work, that is, the person is under the influence of the ugly old man to do bad things, from a process of moving justice to step by step into a robber and thus, 
the natural depiction of the impression of self-interested character was made. This change is very close to the topic of self-interest in Rashomon. There are only three characters in this novel, no matter how severe they are in the troubled times and methods for lingering out, not judging good and evil, but completely revealing the extreme self-interested ideas.

\section{The Construction of Self-interested Thought in Rashomon}

In psychology, self-interest is the only thing that may make anyone pursue or realize as the ultimate goal is his own interests. Although people sometimes care about the happiness and interests of others, this is only a means to pursuit of personal happiness. That is to say, all human behaviors are self-interested motives, and the unselfish behaviors simply don't exist. Any behavior that harms oneself is either pretense or folly. Except for self-satisfaction, people won't really care about others. Everyone who appears in Akutagawa's Rashomon is for his own benefit. Moreover, due to the different environments, this kind of self-interest has some subtle changes in the degree and form of performance.

The protagonist in Rashomon is a representative figure eroded by egoism. Initially, this man was dismissed by the owner and had no way to go, and due to the rainy day, he came to the deserted Rashomon. At that time, the protagonist was wrestling with in the ideological struggle of "starving death" or "being a robber." Is it the good of human nature that triumphs over the dark side of the human heart, or is it self-interest that prevails? In the end, it is the goodness of humanity that overcomes the inner darkness of the protagonist, or self-interest will prevail. According to the plot of the story, the protagonist discovered the old man, after the initial horror, he very hated the behavior of the old man to pull the hair from the dead bodies. This kind of feeling is the revealing of human natural feelings in the face of unethical behavior. Through these naturally revealed feelings, the article describes the feelings of goodness and justice in the hearts of the protagonist, and lays the foundation for the transformation of the inner and lower minds from the good and the evil. At this time, the protagonist completely forgot the ideological struggle that he had fallen into before, and asked the reasons why old man did so.

Out of the inner feelings of good and evil, the protagonist was very angry after listening to the reasons of the old man, which reflects the goodness of human nature. However, the protagonist was gradually being assimilated by egoism because of the excuse of the old man. The idea of becoming a robber once again caught the hearts of the protagonist. Moreover, under the influence of the old man, he found an excuse to do bad things. The courage to be a robber in the hearts of the protagonist was different from the one just now. It is self-interested thinking that caused him to end up being evil. The goodness of the heart of this time was completely defeated by self-interest. If there was no "good" restriction, the "evil" in the inner world would expand as never before. Therefore, the protagonist used survival as an excuse to snatch the old's clothes and became a real bad guy. Moreover, his "evil" was above the "evil" of the old man and the deceased, which can be said to be the most "evil".

The "evil" in the interest is that people are placed in the bad environment; in order to survive in the human nature to make clear will not give in. For example, good people in times of peace can turn into rioters in a time of turmoil. This is the driving force of self-interested thinking.

\section{Conversion of good and evil driven by self-interest}

In Rashomon, Akutagawa Ryunosuke describes the whole process of the fall of an ordinary person driven by egoism. Moreover, by describing the impressions of the characters of "small evil", "evil" and "the most evil", it slowly brings shock to the reader's psychology. On the basis of the influence of self-interest, whether it is against morality or harming the interests of others is a 
stepping stone for self-interest to achieve their own wishes. However, self-interested people will push the responsibility of fault to the external environment and others for their self-esteem while doing bad things. This article describes the vulnerability of people to good deeds and shows their values in the face of self-interest. Therefore, if it is eroded by self-interest, then the interests of others are only a stepping stone to satisfy the material and spirit of the self-interested. In a broad sense, most of human evil can be said to be self-interested on what grounds. Akutagawa brings a vivid self-interest to readers through the form of short stories. After reading the story, readers also feel the terrible nature of self-interest and they may also reflect on their own behaviors, which is one of the reasons why Rashomon has become his masterpiece and has attracted the attention of the world.

The early works of Akutagawa Ryunosuke are mostly short stories of critical egoism. Because he values the weakness of human nature, and most of his works are aimed at exposing cold self-interested ideas. In Rashomon, we can see many of his distinctive descriptions. The expression of this novel is very innovative and unique in the literary world at that time. Moreover, the expression method and style of the novel characters unique to Akutagawa are formed. The social reality of allowing all evil to exist in order to survive is like a breeding ground for self-interest. Self-interest is the ugliest thing hidden in human nature. Perhaps no one can completely overcome it. This is also one of the root causes of various problems in the current society.

\section{Implications for classroom teaching}

The work of Rashomon has carried on an in-depth analysis of some weaknesses of human nature. As far as the author believes, the interpretation and explanation of this work has very important practical value for the cultivation of students' comprehensive character. For example, the work considers poverty to be an important factor in distorting human nature. Liang Xiaosheng, a Chinese writer, once said that compared with affluence, poverty makes it easier for the inferior roots of human nature to be used, and it is easier for people to become dark and full of frustration and hatred towards society. There are four characters in the Rashomon, and they are the employer, the servant, the dead woman and old woman. In order to survive, the employer fired the servant, the servant bullied the old woman, and the old woman succumbed to the dead woman, and the woman deceived the soldier before her death. Their behavior strictly respects the law of the jungle. From them, we can see the ugly side of humanity under the cloak of morality.

The lack of justice is another driving force for humanity to go ugly. Under the social rules, morality is a soft force that binds people's desires. The more stable and harmonious society is, the stronger the binding force of this morality. The law is a hard force. If one's evil touches the bottom line, it will inevitably be punished by law. In the prosperous times, the law can be implemented, but in times of trouble, the role of morality and law is often broken. The evildoers are not punished in the troubled times, the overall morality of the society is retrogressed, and the bottom line is unguarded. Those who are good are often struggling, but those who do evil can get away with murder.

With the development of society and the progress of the times, the wave of economization has swept through every corner of our lives. Under the conditions of commodity economy, people's cognition is often dominated by money. People are in the vortex of economic interests, both good instincts and evil impulses. Most people follow the rules of morality and law and don't dare to be evil. But this doesn't mean that there is no evil power in our society. It doesn't mean that the evil in everyone's heart is completely annihilated. The good and evil of human nature is an ultimate philosophical issue. Is humanity on earth good or bad? Mencius and Xunzi in ancient China have explored this issue, and the dynasties have been arguing over this issue. From the perspective of 
dialectics, good or evil are both two aspects of contradiction, which are both opposite and unified. People are often the unity of good and evil, with dual value orientation, will show different characteristics due to the external environment.

Through the study of Akutagawa's Rashomon, students have a deep understanding of self-interest and human good and evil. In the classroom, students are allowed to interpret some of the behavioral fragments of the servant and the old man in the novels in groups, to explore and analyze the character of the characters and the social background of the characters. In combination with what they have learned, they will have a certain understanding of human nature. At the same time, in this materialistic society, human nature is unfathomable. Good and evil are all in one thought. There are good and evil two small people living in people's heart. How do we adjust? Maybe we'll be confused, and maybe we will lose ourselves and can't recognize our own heart. However, we can strengthen our understanding of ourselves, humanity and society by reading books and reading some excellent literary works.

\section{References}

[l] Yang Rui, Han Zhengyan. On the Self-interested Ridicule in Akutagawa Ryunosuke's Novels [J]. Journal of Shenyang Agricultural University, 2008 (09).

[2] He Fang. Analysis of Akutagawa Ryunosuke's "Rashomon” [J]. Journal of Guizhou Nationalities University.2010 (05).

[3] Yang Xi. Humanity Thinking in Akutagawa Ryunosuke's "Rashomon” [J]. Frontier Economy and Culture. 2011 (02).

[4] Shen Yuan. Analysis of Self-interested Thinking in Akutagawa Ryunosuke's "Rashomon” [J]. Journal of Nanchang College of Education. 2011(12).

[5] Chai Baofen. From the Novel of Akutagawa Ryunosuke to Akira Kurosawa's Film--Analysis of "Rashomon" [J]. Writer, 2009 (02).

[6] Qin Gang. Interpretation of "Rashomon"--From the Novel of Akutagawa Ryunosuke to the Movie of Akira Kurosawa [J].Foreign Literature, 2010(04).

[7] Sun Lichun. The Feminist Interpretation of "The Jungle Beast” [J].Journal of Hangzhou Normal University (Social Science Edition), 2010(03).

[8] Xiao Yanhui. The Selfishness of Human Nature Seen From the "The Jungle Beast” [J]. Harvest, 2011(24).

[9] Yang Di. Analysis of the Narrative Charm of "The Jungle Beast" [J].Journal of Liupanshui Teachers College, 2010(01).

[10] Zhao Yongjun. Seeing Ourselves through the Soul of Others-Appreciation of Akutagawa Ryunosuke's "The Jungle Beast” [J]. Language World (High School Edition), 2006 (11).

[11] Zhou Xingjie. On the Litigation of History_Comparative Appreciation of the Movie "Rashomon" and the Original Work of the Novel [J]. Academic Exchange, 2005(10).

[12] Zhou Yun. Pragmatic Strategies in "The Jungle Beast” [J]. Academic Research, 2003(05). 